\title{
Bacterial Communities in Fecal Samples of Myotis chiloensis from Southern, Chile
}

\author{
Comunidades Bacterianas Presentes en Muestras Fecales \\ de Myotis chiloensis en el Sur de Chile
}

\author{
Kattia Núñez-Montero ${ }^{1,2}$; Andrés Santos ${ }^{1}$; Damián Quezada-Solís ${ }^{1}$; \\ Jaime Martínez-Urtaza ${ }^{3}$; Fulgencio Lisón ${ }^{4,5}$ \& Leticia Barrientos ${ }^{1}$
}

\begin{abstract}
NÚÑEZ-MONTERO, K.; SANTOS, A.; QUEZADA-SOLÍS, D.; MARTÍNEZ-URTAZA, J.; LISÓN, F. \& BARRIENTOS, L. Bacterial communities in fecal samples of Myotis chiloensis from Southern, Chile. Int. J. Morphol., 39(1):57-63, 2021.

SUMMARY: The insectivorous bat Myotis chiloensis is endemic of South America. Even though potentially pathogenic bacterial species of Mycoplasma have been reported from this species, there are no further studies regarding the bacterial communities they harbor. This may provide important insights for the better understanding of its ecology, diet and implications in cross-species pathogens transmission. Here we report a first survey on bacterial communities of $M$. chiloensis based on metagenomic analysis of fecal samples. We found that taxonomic profile is dominated by Proteobacteria (23.7 to $57.7 \%$ ) and Firmicutes (11.8 to 61.6\%), which main families are represented by BurkholderiaceaeEnterobacteriaceae and Veillonellaceae-Bacillaceae, respectively. Phyla Bacteroidetes, Actinobacteria, Cyanobacteria, Planctomycetes and Acidobacteria were also present with abundance above $1 \%$ of the total reads. Variations among individuals could be observed at genus level and no significant differences were found between sex groups regarding taxonomic profiles and diversity. Potentially pathogenic species were also detected in all the samples, including Staphylococcus aureus and Clostridium perfringens. Our results highlight the significance M. chiloensis as a reservoir of pathogenic bacteria and its microbiota as an interesting ecological model due to its wide distribution. Further metagenomic studies are necessary for a better understanding of $M$. chiloensis diet and its host-symbiont relationships.
\end{abstract}

KEY WORDS: Chiroptera; Guano; Metagenomics; Microbiota; Pathogenic bacteria.

\section{INTRODUCTION}

Bats comprises $25 \%$ of living mammalian species - the most abundant group of mammal- exhibiting an extraordinary ecological value as prey and predator, arthropod suppression, seed dispersal, pollination, material and nutrient distribution, and recycle (Banskar et al., 2016b; De Leon et al., 2018). Myotis chiloensis (Waterhouse, 1838) is endemic of South America, along with Histiotus magellanicus, present the southernmost known distribution for any bat in the world (Ossa \& Rodríguez-San Pedro, 2015). M. chiloensis is only found in Chile (from Coquimbo to Navarino Island) and south Argentina (from Neuquén to Tierra del Fuego) (Ossa \& Rodríguez-San Pedro). In south Chile, this bat inhabits native temperate forests and exotic tree plantations - Pinus and Eucalyptus - (Meynard et al., 2014) and is found also in buildings, particularly walls, attics and under the roof (Ossa \& Rodríguez-San Pedro).
Bats can harbor multiple pathogens, viruses have been well-studied (e.g. Rabies, Coronaviruses, Ebolavirus and Paramyxoviruses), however, the role of bats as reservoirs of pathogenic bacteria has been under-explored (Banskar et al., 2016a; Mühldorfer, 2013). Some studies have confirmed the presence of multiple bacterial pathogens in different bat species: by culture-dependent techniques it has been reported putative pathogens belonging to Enterobacteriaceae on Rousettus leschenaultia samples (Banskar et al., 2016a); Bartonella species were studied and isolated from the Finland bat M. daubentonii(Veikkolainen et al., 2014); the presence of Staphylococcus pathogens with high frequency of antimicrobial resistance was reported in guano of Myotis bats (Vandzurová et al., 2012); and Mycoplasmas including potentially novel species- were reported for multiple Chilean bats (Millán et al., 2019).

\footnotetext{
${ }^{1}$ Laboratorio de Biología Molecular Aplicada, Centro de Excelencia en Medicina Traslacional, Universidad de La Frontera, Temuco, Chile.

${ }^{2}$ Centro de Investigación en Biotecnología, Escuela de Biología, Instituto Tecnológico de Costa Rica, Cartago, Costa Rica.

${ }^{3}$ Departament de Genètica i de Microbiologia Facultat de Biociències, Universitat Autònoma de Barcelona, 08193 Bellaterra, Barcelona, Spain.

${ }^{4}$ Laboratorio de Ecología del Paisaje y Conservación, Departamento de Ciencias Forestales, Facultad de Ciencias Agropecuarias y Forestales, Universidad de La Frontera, Temuco, Chile.

${ }_{5}^{5}$ Departamento de Zoología, Facultad de Ciencias Naturales y Oceanográficas, Universidad de Concepción, Concepción, Chile. Kattia Núñez-Montero and Andrés Santos have contributed equally to this work.
} 
Comprehensive studies on the bacterial flora of bats are necessary for a better understanding of its zoonotic threat to humans (Veikkolainen et al.). In fact, this feature has been proposed as an indicator of environmental stress and climate change, since pathogen spreading may be related to habitat alteration and physiological stress (Jones et al., 2009). Recently, changes such as rapid land-use were reported to shift gut microbial communities in bats - because the exposure to novel bacteria or by changing of food resources-, which consequences to host health remain unknown and may have important implications for crossspecies pathogen transmission (Ingala et al., 2019).

Bats have also been recently proposed as a good model for microbiome evolutionary studies in mammals, due to its wide species richness and multiple dietary niches, its important ecological role on seed spreading, and pest control (Lutz et al., 2019). First bacterial community from guano by next-generation sequencing was reported in 2015 (De Mandal et al., 2015). Since then, more reports on microbial diversity from different samples and bats species have been published (Banskar et al., 2016b; De Leon et al.; Dietrich \& Markotter, 2019; Ingala et al.; Selvin et al., 2019). However, studies on bacterial communities associated with bats are still limited, and one of the reasons is the time and cost of sample collection for large-scale studies (Fofanov et al., 2018). To date, there have been no reports on the bacterial symbionts of Myotis chiloensis. Thus, here we described the first survey on metagenomic profiling for bacterial species composition and diversity found on fecal material of the bat Myotis chiloensis.

\section{MATERIAL AND METHOD}

Fieldwork was conducted in November 2017 at Laguna del Laja National Park (WGS84; 19H 286739 E 5858648 S; Bio-Bio, Chile). The wildlife capture and investigation activities of this work were conducted with the ethical approval of the Agricultural and Livestock Service (SAG), Government Administration of Chile, resolution 2770-2017, following the Chilean National laws 4.601 and 19.473. We captured individuals of $M$. chiloensis and directly collected fecal samples from the bats in sterile microtubes under the same conditions. This method (direct fecal sampling from each individual) is more complex limiting the access to suitable number of samples but guarantees a higher and more intact diversity of the sample to be described. All captures were made with the permission of SAG and SNAPE of the Chilean Government. DNA extraction was performed using the PowerSoil DNA Extraction Kit (Qiagen) from fecal samples of two adult males - BC04, BC06- and two adult females - $\mathrm{BC} 02$, BC08 - DNA was amplified using Illustra Genomiphi V2 DNA Amplification kit (GE LifeSciences) to increase the genomic DNA concentration. DNA quality and concentration were verified using Qubit with the Quantifluor ONE dsDNA System kit (Promega), and absorbance ratios at 260/280 and $260 / 230$, respectively. Sequencing of $16 \mathrm{~S}$ rRNA genes was performed with Oxford Nanopore MinION platform using the Rapid 16S Amplicon Barcoding Kit (SQK-RAB201) for library preparation. Sequences were obtained by the MinKNOW suite and basecalling with Guppy 3.0. Reads were filtered by length (>1500 bp) and quality (>10) using NanoFilt 1.1.0 (De Coster et al., 2018), adapters and barcodes were trimmed with qcat-1.1.0. Taxonomic assignment at genus level was carried out with Centrifuge 10.3-beta (Kim et al., 2016), using Silva 132 database (Quast et al., 2013) based on a $95 \%$ of identity threshold, while species level was assigned using Greengenes database (McDonald et al., 2012). Plots and analysis of taxonomic abundance were made with Pavian-0.3 (Breitwieser \& Salzberg, 2020) and MicrobiomeAnalyst (Dhariwal et al., 2017).

\section{RESULTS AND DISCUSSION}

The Chilean myotis (Myotis chiloensis) had a forearm length of $37.8 \pm 0.81$, third finger length of $57.4 \pm 1.5$, fifth finger length of $46.0 \pm 1.0$ and a weight of $6.4 \pm 0.53$. It is a medium size bat with preference for water courses and riparian vegetation. Its roosts are tree holes and houses. Regarding the sequencing results, more than $93 \%$ of those read were successfully classified for the samples (Table I). Common phyla were identified among the samples, including Proteobacteria (from 23.7 to $57.7 \%$ ) and Firmicutes (from 11.8 to $61.6 \%$ ) as more abundant groups, followed by Bacteroidetes, Actinobacteria, Cyanobacteria, Planctomycetes and Acidobacteria with counts above $1 \%$ of the total reads (Fig. 1a). Very similar phyla composition was previously found for bat guano samples in the Cabalyorisa Caves, Philippines (De Leon et al.), with the dominance of Proteobacteria,Actinobacteria, Bacteroidetes, Firmicutes, Chloroflexi, Saccharibacteria and Planctomycetes.

Main families of Proteobacteria were found to be Burkholderiaceae (2.7\% to $16 \%$ ) and Enterobacteriaceae (5.8\% to $12.3 \%$ ), while Firmicutes were mainly represented by Veillonellaceae (2\% to $22.2 \%$ ) and Bacillaceae $(1.8 \%$ to $5.2 \%$ ). Similar results were reported for afrotropical bats, whose gut microbiota was dominated by Proteobacteria (60.4 $\%$ ) and Firmicutes (27.4\%), where Bacillaceae and Enterobacteriaceae were reported to be significantly 
Table I. Collected data for bats during fecal sampling.

\begin{tabular}{llcccccccc}
\hline & & & & \multicolumn{3}{c}{ Gross } & & Net & \multicolumn{2}{c}{ Sequencing data } \\
\cline { 8 - 10 } ID & Specie & Sex & Age & FA & Weight & Size/Weight & Weight & Total Raw & Classified reads \\
\hline BC08 & Myotis chiloensis & Female & Adult & 37.5 & 15.6 & 8.5 & 7.1 & 416217 & $95.3 / 94.3 \%$ \\
BC06 & Myotis chiloen sis & Male & Adult & 36.7 & 14.3 & 8.5 & 5.8 & 131886 & $95.4 / 94.0 \%$ \\
BC04 & Myotis chiloensis & Male & Adult & 38.3 & 15.3 & 8.5 & 6.8 & 51091 & $93.8 / 94.1 \%$ \\
BC02 & Myotis chiloensis & Female & Adult & 36.8 & 14.2 & 8.5 & 5.7 & 20359 & $93.6 / 93.1 \%$ \\
\hline
\end{tabular}

associated with insectivorous bats (Lutz et al.), coincidently with $M$. chiloensis diet. Proteobacteria has also been found as the most abundant phyla independently of the feeding strategy for insectivorous, hematophagous, nectarivores and
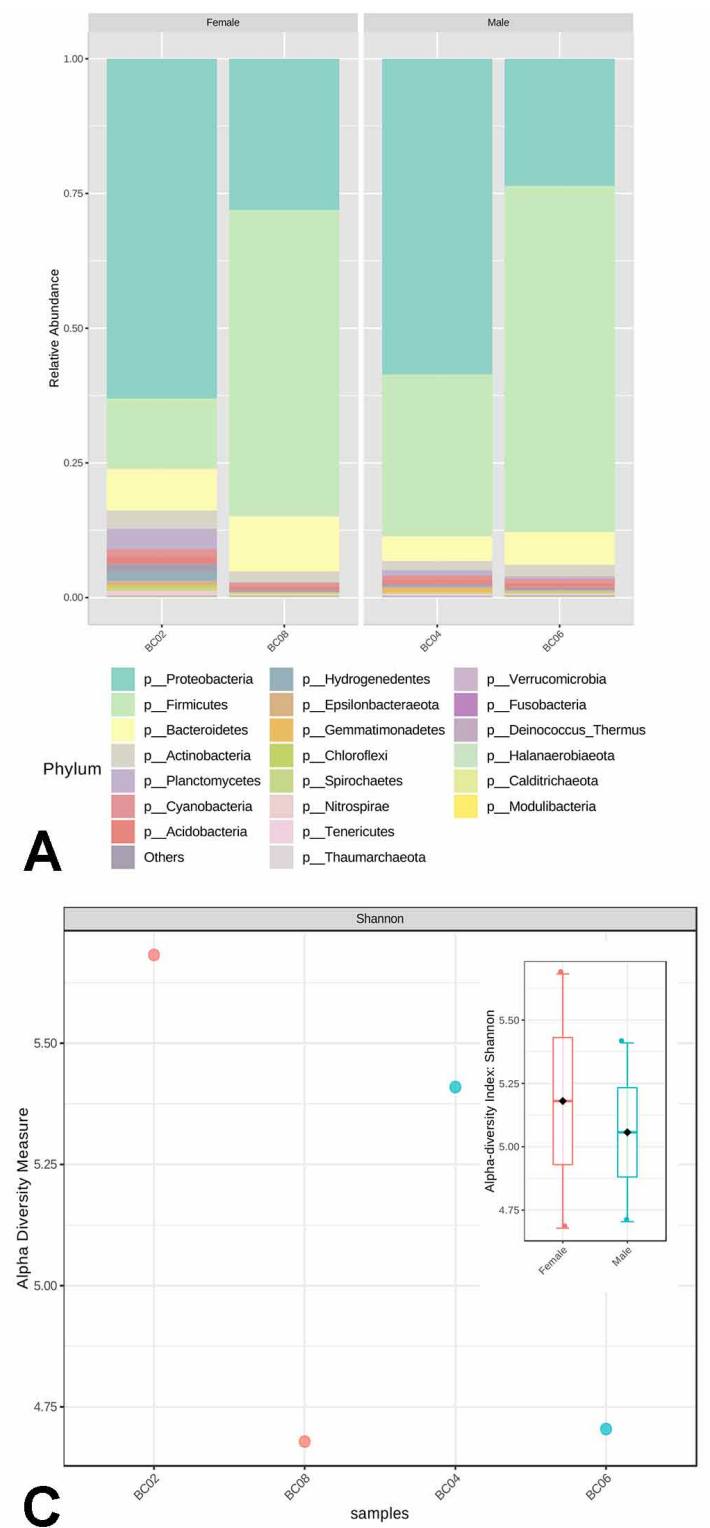

frugivorous bats (Banskar et al., 2016b; Carrillo-Araujo et al., 2015). However, our results showed the major colonization of Firmicutes occurs in some individuals (Fig. 1a). A similar result was only reported in gut of Rhinolophus

- Female
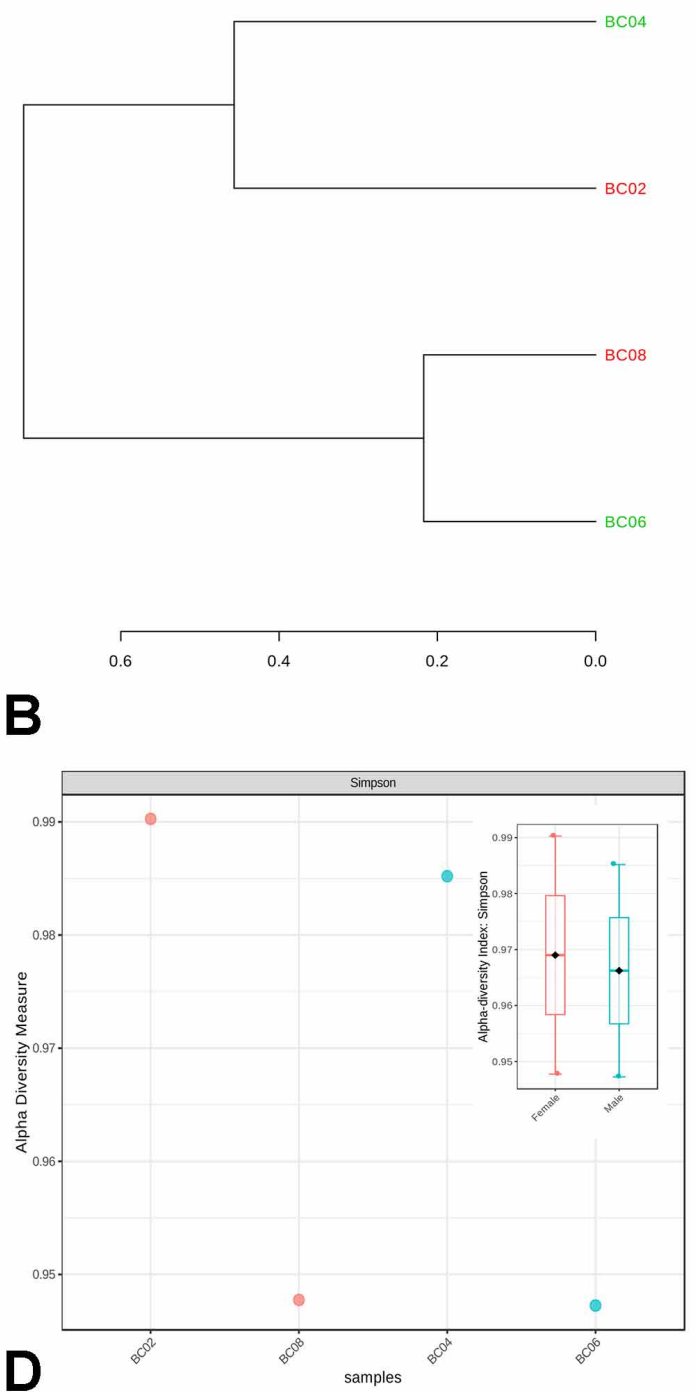

Fig. 1. Microbiome analysis of four fecal samples of Myotis chiloensis: (a) Phylum profiles based on relative abundance of reads; (b) Dendrogram analysis based on Bray-Curtis Index;(c) Alpha-diversity based on Shannon, p-value: 0.86191, [T-test] statistic: 0.19985;(d) Alpha-diversity based on Simpson, p-value: 0.93133, [T-test] statistic: 0.097491. 
monoceros from Meghalaya, India (Selvin et al.), where abundance of Firmicutes $(50.6 \%)$ dominates in some samples. Completely different profiles have also been reported for guano samples from caves in India, where most dominant bacteria belongs to Chloroflexi (29.97\%) and Actinobacteria (22.55 \%) (De Mandal et al.). Even though, dominance of Proteobacteria - particularly Enterobacteriaceae family - have been commonly reported in different bat guano/gut samples (Vengust et al., 2018), this data suggests that due to the vast diversity of bat species and diets, a generalization of bat bacterial communities composition remains impossible to be defined.

Main genera found in Myotis chiloensis are summarized in Table II. All bats share the presence of Bacillus, Escherichia-Shigella and Serratia with similar abundance. Differences in the percentage of the sequences for some groups were found for each individual sample, independent of sex. Sample BC06 showed an increased abundance of Carnobacterium, as well as Dysgonomonas in sample BC08. Sample BC02 showed a reduced percentage of Enterococcus, Staphylococcus and Vagococcus when compared with the other bats and $\mathrm{BCO} 4$ was the only individual with significant presence of Nevskia genus; those might be individual differences related to diet. Studying of individual significant variants on $M$. chiloensis microbiota could be valuable for a better comprehension of each community diet and ecological implications. Further identification of species was conducted with Greengenes taxonomy. Results showed that most abundant species correspond to Janthinobacterium lividum (53.9\%-1.2\%), Serratia marcescens (4.2\% - $1.8 \%)$, Propionibacterium acnes $(2.2 \%-0.8 \%)$, Staphylococcus aureus $(7.5 \%-1.9 \%)$, Veillonella dispar $(8.2 \%-0.6 \%)$, Haemophilus parainfluenzae $(2.2 \%-0.9 \%)$ and Staphylococcus epidermidis (5.8\%-1.2 \%) (Fig. 2). Other potential pathogens were found in less proportion $(<1 \%)$ such as Salmonella enterica, Neisseria cinerea and Clostridium perfringens. Most of these species are usual members of intestinal microbiota on mammals, however, some others can be potentially pathogenic for humans, highlighting the necessity of further studies of $M$. chiloensis as a reservoir of pathogenic bacteria. Potentially pathogenic genera such as Burkholderia, Corynebacterium, Francisella, Legionella, Mycobacterium, Pseudomonas, and Rickettsia were also found on metagenomic data from guano collected in caves (De Leon et al.).

Table II. Comparison of most abundant genera o four Myotis chiloensis fecal samples.

\begin{tabular}{|c|c|c|c|c|c|}
\hline Genera & Female-BC02 & Female-BC08 & Male-BC04 & Male-BC06 & mic lineage \\
\hline Bacillus & $1.58 \%$ & $3.01 \%$ & $3.08 \%$ & $4.70 \%$ & Firmicutes $>$ Bacilli $>$ Bacillales $>$ Bacillaceae \\
\hline Budvicia & $1.27 \%$ & $1.29 \%$ & $1.37 \%$ & $0.56 \%$ & ProteoGammaproteoEnterobacteriales $>$ Enterobacteriaceae \\
\hline Carnobacteriummm & & $0.30 \%$ & $0.66 \%$ & $3.34 \%$ & Firmicutes $>$ Bacilli $>$ Lactobacillales $>$ Carnobacteriaceae \\
\hline Dysgonomonas & $0.36 \%$ & $8.88 \%$ & $1.76 \%$ & $4.21 \%$ & Bacteroidetes $>$ Bacteroidia $>$ Bacteroidales $>$ Dysgonomonadaceaeae \\
\hline Enterobacter & $1.16 \%$ & $1.15 \%$ & $1.13 \%$ & $0.68 \%$ & ProteoGammaproteoEnterobacteriales $>$ Enterobacteriaceae \\
\hline Enterococcus & $0.71 \%$ & $3.92 \%$ & $3.94 \%$ & $8.65 \%$ & Firmicutes $>$ Bacilli $>$ Lactobacillales $>$ Enterococcaceae \\
\hline Escherichia-Shigella & $2.51 \%$ & $2.79 \%$ & $2.42 \%$ & $1.20 \%$ & ProteoGammaproteoEnterobacteriales $>$ Enterobacteriaceae \\
\hline Haliangium & $2.32 \%$ & $0.03 \%$ & $0.34 \%$ & $0.22 \%$ & ProteoDeltaproteoMyxococcales $>$ Haliangiaceae \\
\hline Janthinobacteriummum & $3.81 \%$ & $0.07 \%$ & $2.86 \%$ & $0.71 \%$ & ProteoGammaproteoBetaproteobacteriales $>$ Burkholderiaceae \\
\hline Lactobacillus & $0.21 \%$ & $0.89 \%$ & $0.95 \%$ & $1.56 \%$ & Firmicutes $>$ Bacilli $>$ Lactobacillales $>$ Lactobacillaceae \\
\hline Listeria & & $0.11 \%$ & $0.12 \%$ & $1.19 \%$ & Firmicutes $>$ Bacilli $>$ Bacillales $>$ Listeriaceae \\
\hline Massilia & $3.98 \%$ & $0.20 \%$ & $3.25 \%$ & $0.82 \%$ & ProteoGammaproteoBetaproteobacteriales $>$ Burkholderiaceae \\
\hline Nevskia & & $0.00 \%$ & $2.78 \%$ & $0.00 \%$ & ProteoGammaproteoSalinisphaerales $>$ Solimonadaceae \\
\hline Pseudomonas & $2.68 \%$ & $0.51 \%$ & $2.05 \%$ & $0.58 \%$ & ProteoGammaproteoPseudomonadales $>$ Pseudomonadaceae \\
\hline Serratia & $1.31 \%$ & $1.93 \%$ & $1.40 \%$ & $0.67 \%$ & ProteoGammaproteoEnterobacteriales $>$ Enterobacteriaceae \\
\hline Sporomusa & $0.14 \%$ & $0.92 \%$ & $0.10 \%$ & $0.60 \%$ & Firmicutes $>$ Negativicutes $>$ Selenomonadales $>$ Veillonellaceae \\
\hline Staphylococcus & $0.82 \%$ & $7.82 \%$ & $5.05 \%$ & $5.97 \%$ & Firmicutes $>$ Bacilli $>$ Bacillales $>$ Staphylococcaceae \\
\hline Stenotrophomonas & $1.95 \%$ & $0.14 \%$ & $0.75 \%$ & $0.17 \%$ & ProteoGammaproteoXanthomonadales $>$ Xanthomonadaceae \\
\hline Streptococcus & $0.27 \%$ & $1.27 \%$ & $1.38 \%$ & $1.70 \%$ & Firmicutes $>$ Bacilli $>$ Lactobacillales $>$ Streptococcaceae \\
\hline Sulfuritalea & $0.08 \%$ & $0.03 \%$ & $1.39 \%$ & $0.04 \%$ & ProteoGammaproteoBetaproteobacteriales $>$ Rhodocyclaceae \\
\hline uncultured & $4.44 \%$ & $19.39 \%$ & $1.70 \%$ & $20.31 \%$ & Firmicutes $>$ Negativicutes $>$ Selenomonadales $>$ Veillonellaceae \\
\hline uncultured & $3.31 \%$ & $0.56 \%$ & $1.42 \%$ & $1.44 \%$ & ProteoGammaproteoBetaproteobacteriales $>$ Burkholderiaceae \\
\hline uncultured & $2.34 \%$ & $0.00 \%$ & $0.59 \%$ & $0.27 \%$ & Planctomycetes $>$ Planctomycetacia $>$ Pirellulales $>$ Pirellulaceae \\
\hline uncultured & $2.04 \%$ & $0.02 \%$ & $0.07 \%$ & $0.01 \%$ & ProteoGammaproteoGammaproteobacteria Incertae Sedis $>$ Unknown Family \\
\hline uncultured & $1.70 \%$ & $0.01 \%$ & $0.33 \%$ & $0.21 \%$ & Bacteroidetes $>$ Bacteroidia $>$ Chitinophagales $>$ Saprospiraceae \\
\hline uncultured & $1.31 \%$ & $0.06 \%$ & $0.16 \%$ & $0.07 \%$ & ProteoAlphaproteoRhodobacterales $>$ Rhodobacteraceae \\
\hline uncultured & $0.24 \%$ & $1.32 \%$ & $3.36 \%$ & $0.90 \%$ & ProteoAlphaproteoRhizobiales $>$ Beijerinckiaceae \\
\hline Vagococcus & $0.01 \%$ & $5.79 \%$ & $6.65 \%$ & $4.25 \%$ & Firmicutes $>$ Bacilli $>$ Lactobacillales $>$ Enterococcaceae \\
\hline Veillonella & $0.21 \%$ & $0.95 \%$ & $0.15 \%$ & $0.96 \%$ & Firmicutes $>$ Negativicutes $>$ Selenomonadales $>$ Veillonellaceae \\
\hline
\end{tabular}

Color indicates lower(blue) and higher (red) values in the sample. 

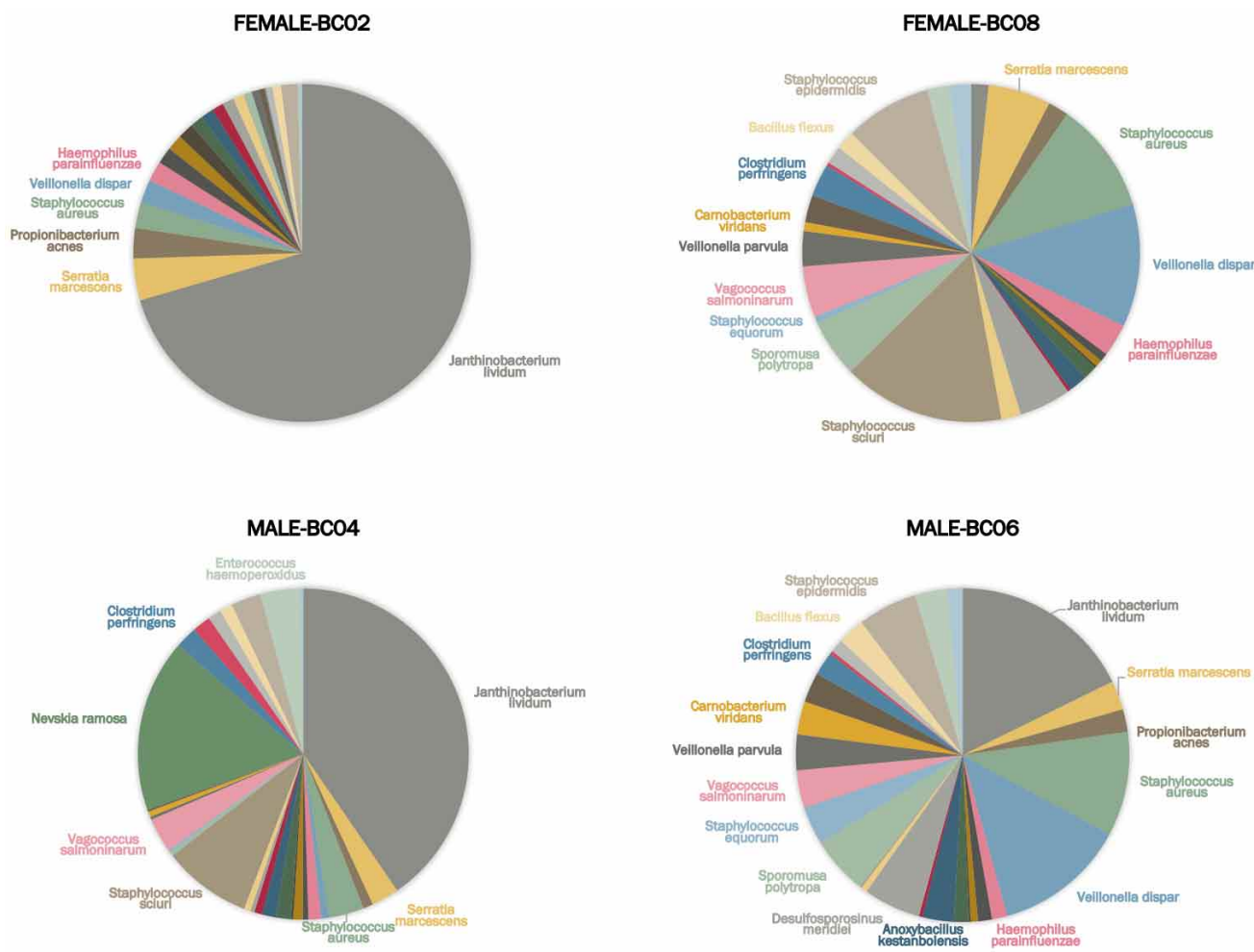

Janthinobacterium lividum

- Serratia marcescens

- Propionibacterium acnes

$\backsim$ Staphylococcus aureus

- Veillonella dispar

- Haemophilus parainfluenzae

- Lysinibacillus boronitolerans

- Acinetobacter johnsonii

- Sphingobium xenophagum

- Bradyrhizobium elkanii

Anoxybacillus kestanbolensis

- Pseudomonas veronii

- Desulfosporosinus meridie

- Plesiomonas shigelloides

- Staphylococcus sciuri

Sporomusa polytropa

- Staphylococcus equorum

- Vagococcus salmoninarum

- Veillonella parvula

- Carnobacterium viridans

- Collinsella aerofaciens

- Nevskia ramosa

- Clostridium perfringens

- Leuconostoc mesenteroides

- Morganella morganii

Bacillus flexus

- Staphylococcus epidermidis

Enterococcus haemoperoxidus

a [Ruminococcus] gnavus

Fig. 2. Comparison of main species found in four Myotis chiloensis fecal samples by $16 \mathrm{~S}$ rARN metagenomics analysis.

This report showed no evidence of deferential microbiomes for males and females of M. chiloensis bats. No differences in species richness were found between groups. In fact, more similar metagenomic profiles were found between individual samples from male $\mathrm{BC} 04$ and female $\mathrm{BC} 02$, as well as for male BC06 and female BC08, which was demonstrated by dendrogram analysis (Fig. 1b) and by alpha-diversity (Fig. 1c-d). Although our data has an optimum percentage of classified reads for the microbiota characterization, it is recommended to compare these results with more replicates, since differences among $\mathrm{BC} 06 / \mathrm{BC} 08$ and $\mathrm{BC} 02 / \mathrm{CB} 04$ could also be attributed to the total reads per sample (Table I). A result on microbiota based on the sex of bats was reported. showing significant differences only when $\mathrm{N}<10$ data set were used (Lutz et al.). Based on these results, sex is not considered as a predictor of the bats microbiome, as other ecological factors such as geographic locality, an important predictor for Afrotropical bats microbiome (Lutz et al.). Diet has been proposed to be a primary factor defining the gut microbiome of bats (Carrillo-Araujo et al.), since it has been evidenced that feeding strategies contribute to the development of different intestinal microbiomes (Carrillo-Araujo et al.; Lutz et al.). Due to the wide distribution of $M$. chiloensis in a variety of ecological niches, it may act as a good model to study the microbiome shifting across geographical regions.
Both Simpson and Shannon indexes showed a high diversity in all the samples ( $>4$ based on Shannon's), which is higher than previously reported for gut bacterial communities of afrotropical bat species and agrees with gut microbiome analysis of Phyllostomid bats (CarrilloAraujo et al.). Differences on bacterial diversity of fecal samples can be explained by host bat species, diet and the sampling method. While other studies on guano have been conducted with guano samples collected from the floor (De Mandal et al.), our study was conducted after direct sampling from individual bats and higher counts of bacteria can be found in fresh fecal samples (Banskar et al., 2016a). Additionally, no clear differences have been observed for bacterial community patterns between insectivorous and frugivorous bats (Banskar et al., 2016b), but higher diversity was reported for insectivores species (Carrillo-Araujo et al.), which is the case of M. chiloensis. In this study we provide a first survey on bacterial communities associated to fecal material of $M$. chiloensis bats, which showed some similarities with previously reported microbiomes of insectivorous bats and the presence of potential pathogens. This data along with further studies on $M$. chiloensis microbiome will provide important insights about the ecology of this species, particularly regarding the better understanding of its diet, host-symbiont relationships, and ecological implications. 


\section{ACKNOWLEDGEMENTS}

This research was funded by the Universidad de La Frontera, Grant DI19-0079; Network for Extreme Environments Research (NEXER), Grant NXR17-0003; Agencia Nacional de Investigación y Desarrollo ANIDGovernment of Chile.Doctoral Grants CONICYT-PFCHA/ Doctorado Nacional/2017-21170263 to K. Núñez-Montero and CONICYT-PFCHA/Doctorado Nacional/201721171392 to A. Santos; Fundación para la Innovación Agraria (FIA). Government of Chile, Grant PYT-2018-0065 "Proyecto BATsignal: Desarrollo de un sistema complementario de control biológico de plagas a través de murciélagos insectívoros para una agricultura más sustentable y adaptada al Cambio Climático".

NÚÑEZ-MONTERO, K.; SANTOS, A.; QUEZADASOLÍS, D.; MARTÍNEZ-URTAZA, J.; LISÓN, F. \& BARRIENTOS, L. Comunidades bacterianas presentes en muestras fecales de Myotis chiloensis en el Sur de Chile. Int. J. Morphol., 39(1):57-63, 2021.

RESUMEN: El murciélago insectívoro Myotis chiloensis es endémico de América del Sur. A pesar de que en esta especie se han reportado bacterias potencialmente patógenas tipo Mycoplasma, no existen estudios sobre sus comunidades bacterianas, lo cual podría proporcionar información importante para una mejor comprensión de su ecología, dieta e implicaciones en la transmisión de patógenos. En el presente trabajo se realiza una descripción de las comunidades bacterianas del murciélago $M$. chiloensis basada en análisis metagenómico de muestras fecales. El perfil taxonómico encontradofue dominado por Proteobacterias $(23,7-57,7 \%)$ y Firmicutes $(11,8-61,6 \%)$, cuyas principales familias fueron representadas por BurkholderiaceaeEnterobacteriaceae y Veillonellaceae-Bacillaceae, respectivamente. También se encontraron los filos Bacteroidetes, Actinobacteria, Cyanobacteria, Planctomycetes y Acidobacteria con una abundancia superior al $1 \%$. Se observaron variaciones entre los individuos a nivel de género, sin diferencias significativas de los perfiles taxonómicos y diversidad según sexo. Se detectaron especies potencialmente patógenas en todas las muestras, entre ellos Staphylococcus aureus y Clostridium perfringens. Nuestros resultados destacan la importancia de $M$. chiloensis como un reservorio de bacterias patógenas y el estudio de su microbiota como un modelo ecológico debido a su amplia distribución. Más estudios metagenómicos son necesarios para comprender la dieta de $M$. chiloensis y sus relaciones huésped-simbionte.

PALABRAS ClAVE: Chiroptera; guano; Metagenómica; Microbiota; Bacterias patógenas.

\section{REFERENCES}

Banskar, S.; Bhute, S. S.; Suryavanshi, M. V.; Punekar, S. \& Shouche, Y. S. Microbiome analysis reveals the abundance of bacterial pathogens in Rousettus leschenaultii guano. Sci. Rep., 6:36948, $2016 \mathrm{a}$.

Banskar, S.; Mourya, D. T. \& Shouche, Y. S. Bacterial diversity indicates dietary overlap among bats of different feeding habits. Microbiol. Res., 182:99-108, 2016b.

Breitwieser, F. P. \& Salzberg, S. L. Pavian: interactive analysis of metagenomics data for microbiome studies and pathogen identification. Bioinformatics, 36(4):1303-4, 2020.

Carrillo-Araujo, M.; Tas s, N.; Alcántara-Hernández, R. J.; Gaona, O.; Schondube, J. E.; Medellín, R. A.; Jansson, J. K. \& Falcón, L. I. Phyllostomid bat microbiome composition is associated to host phylogeny and feeding strategies. Front. Microbiol., 6:447, 2015.

De Coster, W.; D’Hert, S.; Schultz, D. T.; Cruts, M. \& Van Broeckhoven, C. NanoPack: visualizing and processing long-read sequencing data. Bioinformatics, 34(15):2666-9, 2018.

De Leon, M. P.; Montecillo, A. D.; Pinili, D. S.; Siringan, M. A. T. \& Park, D. S. Bacterial diversity of bat guano from Cabalyorisa Cave, Mabini, Pangasinan, Philippines: A first report on the metagenome of Philippine bat guano. PLoS One, 13(7):e0200095, 2018.

De Mandal, S.; Zothansanga; Panda, A. K.; Bisht, S. S. \& Kumar, N. S. First report of bacterial community from a Bat Guano using Illumina next-generation sequencing. Genom. Data, 4:99-101, 2015.

Dhariwal, A.; Chong, J.; Habib, S.; King, I. L.; Agellon, L. B. \& Xia, J. MicrobiomeAnalyst: a web-based tool for comprehensive statistical, visual and meta-analysis of microbiome data. Nucleic Acids Res., 45(W1):W180-8, 2017.

Dietrich, M. \& Markotter, W. Studying the microbiota of bats: Accuracy of direct and indirect samplings. Ecol. Evol., 9(4):17305, 2019.

Fofanov, V. Y.; Furstenau, T. N.; Sanchez, D.; Hepp, C. M.; Cocking, J.; Sobek, C.; Pagel, N.; Walker, F. \& Chambers, C. L. Guano exposed: Impact of aerobic conditions on bat fecal microbiota. Ecol. Evol., 8(11):5563-74, 2018.

Ingala, M. R.; Becker, D. J.; Holm, J. B.; Kristiansen, K. \& Simmons, N. B. Habitat fragmentation is associated with dietary shifts and microbiota variability in common vampire bats. Ecol. Evol., 9(11):6508-23, 2019.

Jones, G.; Jacobs, D. S.; Kunz, T. H.; Wilig, M. R. \& Racey, P. A. Carpe noctem: the importance of bats as bioindicators. Endanger. Species Res., 8:93-115, 2009.

Kim, D.; Song, L.; Breitwieser, F. P. \& Salzberg, S. L. Centrifuge: rapid and sensitive classification of metagenomic sequences. Genome Res., 26(12):1721-9, 2016.

Lutz, H. L.; Jackson, E. W.; Webala, P. W.; Babyesiza, W. S.; Kerbis Peterhans, J. C.; Demos, T. C.; Patterson, B. D. \& Gilbert, J. A. Ecology and host identity outweigh evolutionary history in shaping the bat microbiome. MSystems, 4(6):e00511-19, 2019.

McDonald, D.; Price, M. N.; Goodrich, J.; Nawrocki, E. P.; DeSantis, T. Z.; Probst, A.; Andersen, G. L.; Knight, R. \& Hugenholtz, P. An improved Greengenes taxonomy with explicit ranks for ecological and evolutionary analyses of bacteria and archaea. ISME J., 6(3):610-8, 2012.

Meynard, C. N.; Soto-Gamboa, M.; Heady III, P. A. \& Frick, W. F. Bats of the Chilean temperate rainforest: patterns of landscape use in a mosaic of native forests, eucalyptus plantations and grasslands within a South American biodiversity hotspot. Biodivers. Conserv., 23:1949-63, 2014. 
Millán, J.; Cevidanes, A.; Sacristán, I.; Alvarado-Rybak, M.; Sepúlveda, G.; Ramos-Mella, C. A. \& Lisón, F. Detection and characterization of hemotropic mycoplasmas in bats in Chile. $J$. Wildl. Dis., 55(4):977-81, 2019.

Mühldorfer, K. Bats and bacterial pathogens: a review. Zoonoses Public Health, 60(1):93-103, 2013.

Ossa, G. \& Rodríguez-San Pedro, A. Myotis chiloensis (Chiroptera: Vespertilionidae). Mamm. Species, 47(922):51-6, 2015.

Quast, C.; Pruesse, E.; Yilmaz, P.; Gerken, J.; Schweer, T.; Yarza, P.; Peplies, J. \& Glöckner, F. O. The SILVA ribosomal RNA gene database project: improved data processing and web-based tools. Nucleic Acids Res., 41(Database issue):D590-6, 2013.

Selvin, J.; Lanong, S.; Syiem, D.; De Mandal, S.; Kayang, H.; Kumar, N. S. \& Kiran, G. S. Culture-dependent and metagenomic analysis of lesser horseshoe bats' gut microbiome revealing unique bacterial diversity and signatures of potential human pathogens. Microb. Pathog., 137:103675, 2019.

Vandžurová, A.; Pilis, V.; Backor, P.; Júdová, J.; Javorsk, P. \& Faix, S. P. P. Microflora of the bat guano. Folia Vet., 56(2):68-9, 2012.

Veikkolainen, V.; Vesterinen, E. J.; Lilley, T. M. \& Pulliainen, A. T. Bats as Reservoir Hosts of Human Bacterial Pathogen, Bartonella mayotimonensis. Emerg. Infect. Dis., 20(6):960-7, 2014.

Vengust, M.; Knapic, T. \& Weese, J. S. The fecal bacterial microbiota of bats; Slovenia. PLoS One, 13(5):e0196728, 2018.

Waterhouse, G. The Zoology of the Voyage of H.M.S. Beagle, under command of Capt. Fitzroy, during the years 1832 to 1836. In: Darwin, C. (Ed.). Part II: Mammalia. London, Annals and Magazine of Natural History, Smith, Elder \& Co., 1838.
Corresponding author:

Leticia Barrientos

Laboratorio de Biología Molecular Aplicada

Centro de Excelencia en Medicina Traslacional

Universidad de La Frontera

Temuco

CHILE

Email: leticia.barrientos@ufrontera.cl

Received: 28-08-2020

Accepted: 17-09-2020 